\title{
Metabolism or behavior: explaining the performance of aphids on alkaloid-producing fungal endophytes in annual ryegrass (Lolium multiflorum)
}

\author{
Daniel A. Bastias ${ }^{1}\left({ }^{10}\right.$ - Andrea C. Ueno ${ }^{1}$. Cristina R. Machado Assefh ${ }^{2,3}$. \\ Adriana E. Alvarez ${ }^{3} \cdot$ Carolyn A. Young $^{4} \cdot$ Pedro E. Gundel $^{1}$
}

Received: 1 April 2016 / Accepted: 24 August 2017

(C) Springer-Verlag GmbH Germany 2017

\begin{abstract}
Plant-herbivore interactions are often mediated by plant microorganisms, and the "defensive mutualism" of epichloid fungal endophytes of grasses is an example. These endophytes synthesize bioactive alkaloids that generally have detrimental effects on the performance of insect herbivores, but the underlying mechanisms are not well understood. Our objective was to determine whether changes in the physiology and/or behavior of aphids explain the changes in performance of insects feeding on endophytic plants. We studied the interaction between the aphid Rhopalosiphum padi and the annual ryegrass Lolium multiflorum symbiotic $(\mathrm{E}+)$ or not symbiotic $(\mathrm{E}-)$ with the fungus Epichloë occultans that can synthesize loline alkaloids. We hypothesized that aphids feeding on E+ plants have higher energetic demands for detoxification of fungal alkaloids, thereby negatively impacting the individual performance, population growth, and structure. Aphids growing on $\mathrm{E}+$
\end{abstract}

Communicated by Evan Siemann.

Electronic supplementary material The online version of this article (doi:10.1007/s00442-017-3940-2) contains supplementary material, which is available to authorized users.

Daniel A. Bastias

dabastia@agro.uba.ar

1 IFEVA, Consejo Nacional de Investigaciones Científicas y Técnicas, Universidad de Buenos Aires, Av. San Martín 4453, C1417DSE Buenos Aires, Argentina

2 CONICET-CCT Salta, Avda. Bolivia 5150, A4408FVY Salta, Argentina

3 Cátedra de Química Biológica, Facultad de Ciencias Naturales, Universidad Nacional de Salta (UNSa), Avda. Bolivia 5150, A4408FVY Salta, Argentina

4 The Samuel Roberts Noble Foundation, 2510 Sam Noble Parkway, Ardmore, OK 73401, USA plants had lower values in morphometric and functional variables of individual performance, displayed lower birth rate, smaller population size, and dramatic structural changes. However, aphids exhibited lower values of standard metabolic rate (SMR) on E+ plants, which suggests no high costs of detoxification. Behavioral variables during the first $8 \mathrm{~h}$ of feeding showed that aphids did not change the phloem sap ingestion with the presence of fungal endophytes. We hypothesize that aphids may maintain phloem sap ingestion according to their fungal alkaloid tolerance capacity. In other words, when alkaloid concentrations overcome tolerance threshold, ingestion of phloem should decrease, which may explain the observed lower values of SMR in E+ feeding aphids.

Keywords Endophyte - Symbiosis - Metabolic rate · Insect behavior $\cdot$ Fitness $\cdot$ EPG technique

\section{Introduction}

Coevolution between plants and herbivorous insects has resulted in an ample repertoire of plant defenses (physical, chemical, and developmental characters) and in equally ample counter-defenses of herbivores (Schoonhoven et al. 2005; Speed et al. 2015). However, the relationship between defenses and counter-defenses may not always be straightforward because it can be mediated by "hidden factors" like the symbionts of plants (Saikkonen et al. 2013; Pieterse et al. 2014). The interaction of plants with microorganisms results in phenotypic changes that may render the hosts more tolerant to herbivores (Schoonhoven et al. 2005; Pineda et al. 2010). For example, symbiotic microorganisms of roots can increase the tolerance to herbivores by activating plant defensive mechanisms (Bennett et al. 2006; Pozo 
and Azcón-Aguilar 2007; Koricheva et al. 2009). In addition, the leaf fungal endophytes of the genus Epichloë, symbionts of cool-season grasses that are considered as an example of "defensive mutualist," are able to synthesize chemical compounds that give protection to their host plants against vertebrate and invertebrate herbivores (Clay 1988; Popay and Bonos 2005; White and Torres 2009; Saikkonen et al. 2013). In spite of the clear involvement of the microorganisms on plant-herbivore interaction, the defenses provided by the symbiotic microorganisms to host plants have been rarely incorporated into models of herbivore ecophysiology.

Nitrogen has been recognized as a key element for herbivorous insects because its concentration in plants (2-4\%) is proportionally lower than in insects (8-14\%), and consequently, it has been frequently used as a measurement of plant quality (Karban and Agrawal 2002; Schoonhoven et al. 2005). Nonetheless, the characterization of plant quality by means of total $N$ may not be always valid because certain nitrogenous compounds are toxic allelochemicals such as alkaloids, glucosinolates, or cyanogenic glucosides (Schoonhoven et al. 2005; Walters 2011). This is particularly important in plant-microorganism symbiotic relationships where the production of $\mathrm{N}$-based toxic compounds by the symbionts can dramatically change the quality of host plants (Clay 1988; White and Torres 2009; Saikkonen et al. 2013). Alkaloids are synthesized either from the amino acids ornithine, lysine, phenylalanine, tyrosine, tryptophan, and histidine, or from purines and pyrimidines (Karban and Agrawal 2002; Walters 2011). In addition to the plants own production of allelochemicals, symbiotic microorganisms can also be a source of secondary bioactive compounds. Epichloë fungal endophytes of grasses contain genes for the synthesis of bioactive alkaloids (Saikkonen et al. 2013; Schardl et al. 2013b; Young et al. 2015). Four types have been described, ergot alkaloids (i.e., ergopeptine and ergovaline), indolediterpenes (i.e., lolitrem B and terpendoles), pyrrolizidines (i.e., lolines), and peramine (Schardl et al. 2012, 2013b; Panaccione et al. 2014; Young et al. 2015). The effectiveness of alkaloids depends upon the identity of the herbivore. For instance, ergot alkaloids and indole-diterpenes are effective to a broad spectrum of vertebrates and invertebrates, while pyrrolizidines and peramines are effective on insects (Wilkinson et al. 2000; Johnson et al. 2013; Gundel et al. 2013; Schardl et al. 2013b). Although the anti-herbivory mechanisms of grasses may be more related to avoidance and tolerance (Karban and Baldwin 1997), Epichloë species endow host plants with a powerful and diverse mechanism of resistance (Clay 1988; Simons et al. 2008; White and Torres 2009; Saikkonen et al. 2013).

Herbivorous insects are continuously sensing the quality of food as a way to balance their daily nutritional and energetic requirements. In this regard, plant toxins are challenging because insects have to minimize their toxic effects, and at the same time, maximize the intake of nutrients (Karban and Baldwin 1997; Schoonhoven et al. 2005; Ibanez et al. 2012). In order to cope with toxins, insects have evolved strategies at biochemical, physiological, and behavioral levels; for instance, insects can metabolize allelochemicals into non-toxic compounds, and/or they can decrease the level of ingestion of food (Phillips 1984; Simpson and Abisgold 1985; Rollo and Hawryluk 1988; Rueda et al. 1991; Schoonhoven et al. 2005; Després et al. 2007; strategies are comprehensively reviewed in Herrera and Pellmyr 2002). However, if the level of toxins is high, these strategies could ultimately affect the fitness of insects. According to the "metabolic load hypothesis," when the biochemical detoxification achieves a high energetic cost with respect to other physiological processes, the allocation of energy to processes such as growing and reproduction may be compromised (Cresswell et al. 1992; Karban and Agrawal 2002). On the other hand, when the reduction of food ingestion (e.g., due to mechanical failures during the feeding, and/ or reduced feeding time) achieves a level where the daily energetic requirements are not met, growth and reproduction will be compromised (Neal 1987; Appel and Martin 1992; van Loon 1993; Behmer et al. 1999). In the particular case of the plant-endophyte interaction, although several studies have shown the negative effects of fungal alkaloids on fitness of generalist aphids (Johnson et al. 1985; Eichenseer et al. 1991; Wilkinson et al. 2000; Bultman et al. 2004; Meister et al. 2006; Simons et al. 2008; Gundel et al. 2012; Ueno et al. 2015), the underlying mechanisms, either physiological or behavioral, are still unclear.

Our objective was to determine whether changes in the aphids' physiology and/or behavior explain the reduced fitness observed when feed on grasses hosting endophytic Epichloë species. We utilized the generalist sap-sucking herbivore Rhopalosiphum padi and the annual (Italian) ryegrass Lolium multiflorum in symbiosis with the endophyte Epichloë occultans, a loline-producing fungus (Sugawara et al. 2006; Moore et al. 2015). It has been previously shown the negative effects of loline alkaloids (Wilkinson et al. 2000) and in particular, of the fungal endophyte $E$. occultans (Omacini et al. 2001; Miranda et al. 2011; Gundel et al. 2012; Ueno et al. 2015) on the performance of $R$. padi aphids. Experiments were conducted to understand the specific parameters of aphid performance that could be influenced by the endophyte at the individual and population levels. We hypothesize that aphids feeding on endophytesymbiotic plants will have higher metabolic rates as result of the detoxification of fungal alkaloids, impacting negatively on insect individual performance (weight-length, fecundity, and life span), birth rate, population growth, and structure. In addition, to compensate the toxic effects of alkaloids, we expected changes in aphid penetration and feeding behavior, enhancing the stylet penetration on plant tissues and 
increasing the ingestion of phloem. In this study, we report for first time the endophyte effects on the metabolic rate (a measure of the physiological state and of energetic budget) and on the aphid behavior of stylet penetration on plant tissues. Our study contributes to our understanding of the underlying mechanisms involved in reduced aphid fitness as a consequence of feeding on grasses in symbiosis with loline-producing fungal endophytes.

\section{Materials and methods}

\section{Plant and aphid material}

Plants: Endophyte-symbiotic and non-symbiotic plants were generated from one common population frequently harvested from a successional pampean grassland (Argentina) $\left(36^{\circ} 00^{\prime} \mathrm{S}, 61^{\circ} 5^{\prime} \mathrm{W}\right)$. Prior to sowing, $1 \mathrm{~g}$ of seeds $(\approx 500$ seeds) was treated with a systemic fungicide (Triadimenol $150 \mathrm{~g} / \mathrm{kg}$; Baytan ${ }^{\circledR} \mathrm{T}$ ) to kill the endophytic symbiont. Fungicide-treated and -untreated seeds were sown in contiguous plots $\left(1 \mathrm{~m}^{2}\right)$ in order to multiply seeds. Plants were allowed to exchange pollen during flowering to avoid segregation between populations. At physiological maturity, seeds from both plots were separately harvested. The frequency of endophyte-symbiotic seeds in each lot was examined by microscopy after staining the seeds with Rose Bengal (Bacon and White 1994). After evaluating the success of the fungicide treatment (99\%), we refer to the seed or plants as endophyte-symbiotic (E+) and non-symbiotic (E-). Additionally, the symbiotic status of all the experimental plants was confirmed by looking for stained endophyte hyphae in the sheath base of the outer leaf under light microscope (Bacon and White 1994). We did not observe any fungicidal effect on the experimental plants. A total of 126 plants $(65 \mathrm{E}+$ and 61E-) were used for all our experiments.

Parameters related with the biomass quality of E+ and E- plants are presented in Table 1. Since nitrogen (N) tissue content is usually an important parameter determining the plant quality for herbivores (Karban and Agrawal 2002; Schoonhoven et al. 2005), we evaluated the contents of $\mathrm{N}$ and additionally, the water and carbon (C) contents

Table 1 Parameters of biomass quality of symbiotic $(\mathrm{E}+; n=3)$ and non-symbiotic (E-; $n=3$ ) Lolium multiflorum plants with the fungus Epichloë occultans

\begin{tabular}{lrr}
\hline Variable & \multicolumn{1}{l}{ E+ } & \multicolumn{1}{l}{ E- } \\
\hline Water content $(\%)$ & $79.51(2.59)$ & $80.58(3.94)$ \\
$\mathrm{N}(\%)$ & $3.48(0.53)$ & $3.78(0.89)$ \\
$\mathrm{C}: \mathrm{N}(\%)$ & $12.86(1.77)$ & $13.11(4.11)$ \\
\hline
\end{tabular}

Values are mean $\pm S E$ on three E+ and three E- L. multiflorum plants (10 weeks, at tillering stage) from our experimental plants. Due to a previous study did not detect significant differences in terms of $\mathrm{N}$ content using the same model system (same origin population of Lolium multiflorum and its Epichloë occultans fungal endophyte) (Omacini et al. 2009), we only harvested tissues from three plants for each biotype. For the water content, the aboveground plant tissues were harvested and weighed and then dried in an oven $\left(60{ }^{\circ} \mathrm{C}\right)$ for $48 \mathrm{~h}$, and weighed again. Water content represents the percentage of water on fresh basis (dry matter + water). For $\mathrm{N}$ and $\mathrm{C}$ determinations, a leaf sample was taken from each individual plant. $\mathrm{N}$ and $\mathrm{C}$ represent the percentage of these elements on the same plant determined by an elemental analyzer (LECO model TruSpec CHNS, Wicklow, Ireland).

Aphids: Individuals of the bird cherry-oat aphid R. padi (L.) were collected from the experimental field of the Institute IFEVA - CONICET, Facultad de Agronomía, Universidad de Buenos Aires ( $\left.34^{\circ} 35^{\prime} 28.37^{\prime \prime} \mathrm{S}, 58^{\circ} 28^{\prime} 47.54^{\prime \prime} \mathrm{W}\right)$. The aphid colony was established from a founder population of 200 apterous adult aphids reared under controlled conditions $\left[2{ }^{\circ} \mathrm{C}( \pm 1)\right.$, photoperiod L12:D12 $\mathrm{h}$, and radiation $150 \mu \mathrm{mol} \mathrm{m}{ }^{-2} \mathrm{~s}^{-1}$ ] on wheat (cultivar Cronox; Don Mario), a plant species that is infected naturally by $R$. padi. Individual aphids from that colony were used in all our experiments.

Symbiont: Total DNA extracted from seed (94 individual seeds) from the original population was used to characterize the endophyte using PCR with primers specific to the known alkaloid biosynthesis genes from Epichloë species according to the methodology in (Takach and Young 2014; Charlton et al. 2014). The presence of the alkaloid biosynthesis genes required for ergot alkaloids, indole-diterpenes, lolines, and peramine is indicative of the potential for any given Epichloë species to produce these alkaloids (Schardl et al. 2013c). In the annual ryegrass samples, we detected genes required for indole-diterpenes, lolines, and peramine. The molecular analysis of the endophyte-infected seeds confirmed the presence of an endophyte, consistent with Epichloë occultans, the common loline-producing endophyte of annual ryegrasses (Moon et al. 2000; Schardl et al. 2013a). Similar to a recent survey of alkaloids in annual ryegrasses from Australia (Moore et al. 2015), all our endophyte-infected seeds contained identical alkaloid gene marker profile and were predicted to produce peramine, indole-diterpenes such as terpendoles, and lolines, such as $\mathrm{N}$-formylloline. Although E. occultans has the perA gene encoding the enzyme required for the biosynthesis of peramine, an alkaloid known to deter insects (see e.g., Fuchs et al. 2013), the metabolite has remained undetected in different analyses made on our ryegrass plants (unpublished data) and may reflect that the gene although present, is non-functional (Berry et al. 2015). 


\section{Experiments}

\section{Endophyte effect on aphid population dynamics and structure}

The first experiment was carried out to evaluate the effect of $\mathrm{E}+$ plants on the population dynamics and structure of the aphid $R$. padi. The population size was evaluated by counting the number of aphids in each plant every 3 days until population growth stopped (day 25, see Fig. 1). The structure of the population was characterized by classifying the aphids in three morphs (nymphs, apterous adults, and winged adults) (Patch 1917), and the number of each morph was measured. The structure of populations reflects its growth potential. Populations composed of a higher proportion of no-winged than winged aphids grow more rapid due to that the former individuals have faster growth and bigger offspring (Müller et al. 2001). Sixteen individual plants of L. multiflorum symbiotic ( $8 \mathrm{E}+$ ) with the endophyte and endophyte free $(8 \mathrm{E}-)$ were grown in 0.5 -L pots (soil, sand, and peat). Initially, three seeds were sown, but only one seedling per pot was kept (the other two were removed) after confirming the symbiotic status of seedlings (either E+ or E-) (see above). Plants were kept outdoors, periodically watered, and grown without fertilization. When plants had about $4-5$ tillers, each one was infested with 10 adult aphids (no-winged) from our colony. Even though colonization of new host plant in nature is usually carried out by one emigrant (winged or apterous) adult aphid (Oliver et al. 2007), 10 individuals were enough to secure the establishment of all the experimental colonies. In order to prevent aphids from escaping, each plant was enclosed with a white voile bag supported with a plastic tubular net.

\section{Endophyte effect on individual aphid performance and development}

Two newly molted adults and no-winged aphids were transferred from our colony to $25 \mathrm{E}+$ and $25 \mathrm{E}$ - plants (two aphids per plant). Plants were tillering (6 weeks) and were grown as set up in experiment 1. Each individual aphid was placed on the oldest leaf (from one tiller) confined in a transparent clip cage $(4 \times 2.5 \mathrm{~cm}$ base, $2 \mathrm{~cm}$ height $)$ held with a rubber band. In turn, each cage was attached to a wooden stake anchored to the potting soil. Thus, each plant contained two clip cages with one aphid per cage, and cages were places on two different tillers. The experiment started with the first nymph produced by each mother aphid confined in the clip cage. To avoid the potential maternal effect carried out by mother aphids grown on other plant species (wheat), mothers were immediately removed. The experiment was carried out outdoors, but plants were covered with a plastic ceiling to protect them from rain. Plants were watered as necessary. Observations were performed daily until the death of the adult aphid, counting and removing offspring and molts (if were observed). For each individual, we recorded: (1) the time from first nymphal instar until mature adult (nymph life span, development), (2) the time as adult aphid until death (adult life span, development), (3) the number of born aphids (fecundity), (4) the daily birth rate estimated as the average number of nymphs produced per day during the reproductive period, (5) length, and (6) weight (adults were individually weighted, and nymphs were

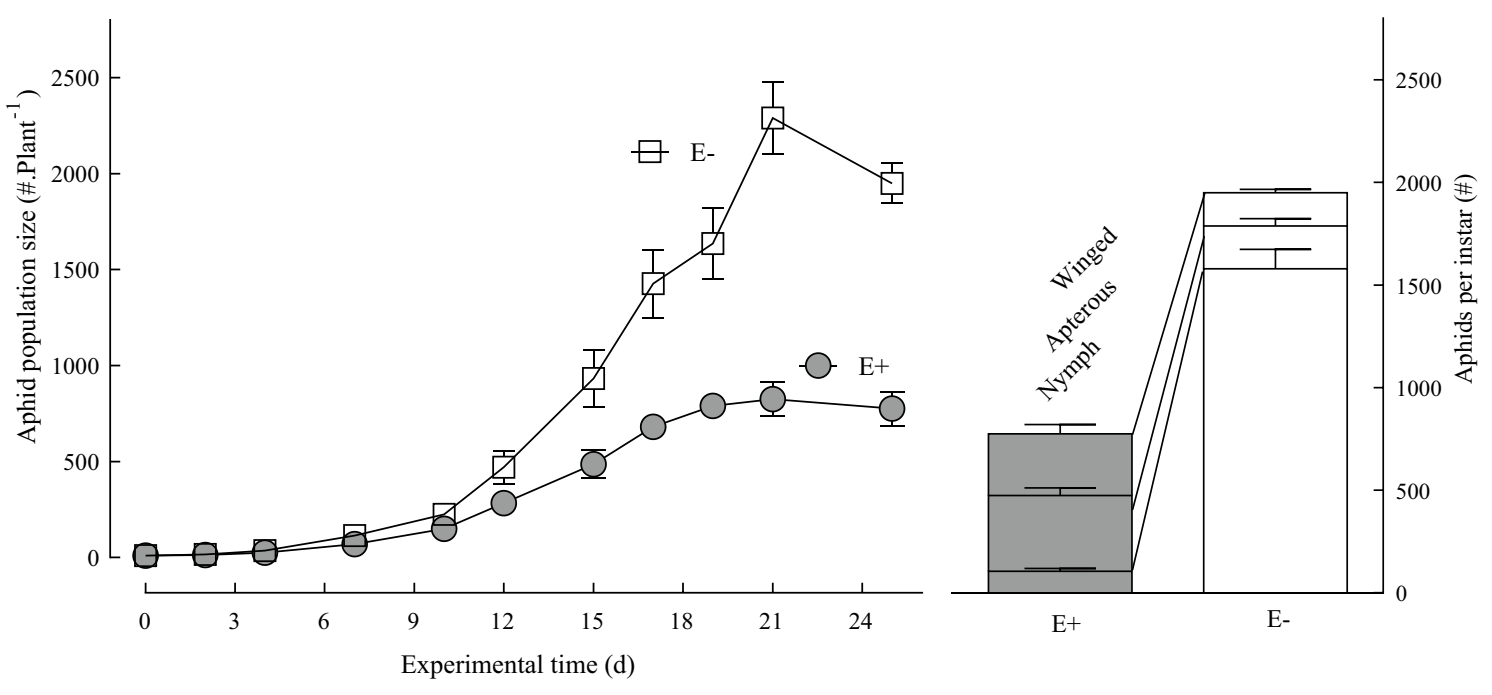

Fig. 1 Population dynamics of the aphid Rhopalosiphum padi feeding on symbiotic (8 E+) and non-symbiotic (8 E-) Lolium multiflorum plants with the fungus Epichloë occultans. Number of aphids in each instar (nymph, apterous and winged adults) at the end of the experiment is shown on the right. Values are mean $\pm \mathrm{SE}$ 
weighted in groups of 10 individuals). Aphid weight has been positively correlated with aphid fitness (Traicevski and Ward 1994; Su et al. 2006).

\section{Endophyte effect on aphid feeding behavior}

Electrical Penetration Graph (EPG). The EPG technique (McLean and Kinsey 1964; Tjallingii 1978, 1985, 1988) was used to monitor the probing and feeding behavior of apterous adult $R$. padi aphids on L. multiflorum plants (E+ and $\mathrm{E}-$ ). This tool was used to study the plant penetration by the aphid's stylets. The plant and the insect were made part of an electrical circuit, by inserting a wire into the soil of a potted plant and attaching a gold wire to the aphid dorsum. When the aphid started probing (inserting the stylets in the plant), the circuit was closed and electrical signals were received on a recording system. EPG signals (referred to as "waveforms") are the result of voltage fluctuations due to aphids' activities and are correlated with tissue locations of the stylet tips (Kimmins and Tjallingii 1985; Tjallingii 1985, 1988; Tjallingii and Esch 1993). Measurements were performed with a Giga-8 device (Wageningen University, Wageningen, the Netherlands), during the first $8 \mathrm{~h}$ of contact between aphids and grasses. Before being used in the experiment, aphids were reared on wheat plants in order to avoid a behavioral bias toward E+ or E- plants; hence, aphids could not acclimatize in advanced to any of the test plants. Four plants, two E- and two E+, were placed in a Faraday cage; probing and feeding behavior of two aphids on each plant was recorded simultaneously during $8 \mathrm{~h}$. From 8 rounds of recordings, 18 and 22 successful replicates were obtained for E- and E+, respectively. New plants and aphids were used on each round. Aphids were placed on the abaxial side of the first fully expanded leaf. Before the plant exposure, each aphid was attached with the gold wire electrode (diameter $20 \mu \mathrm{m}, 2-$ to $3-\mathrm{cm}$ long) using a water-based silver glue and immobilized by a vacuum-suction device. The other end of the gold wire was attached to a 3-cm-long copper wire (diameter $0.2 \mathrm{~mm}$ ), which was connected to the input of the head stage amplifier with a 1 giga-ohm input resistance and 50× gain. The plant electrode, a 2-mm-thick, 10-cm-long copper rod, was inserted into the soil of the potted plant and connected to the plant voltage output of the EPG device. The experiment was maintained under laboratory conditions $\left(20 \pm 2{ }^{\circ} \mathrm{C}\right.$ and constant light). Data acquisition was performed with Stylet+_2013 software, and the waveform analyses were done by Stylet v01.23 software (EPG Systems, http://www. epgsystems.eu/downloads.php).

EPG waveforms and variables. The EPG signals were analyzed by distinguishing six waveforms related to aphid activities: (1) $\mathrm{C}$ reflects the first electrical stylet contact with the epidermis, intercellular sheath salivation in epidermis and mesophyll, and stylet movements and salivary sheath formation in all plant tissues; (2) pd is the potential drop that reflects brief intracellular stylet punctures and is also included as part of event C; (3) F reflects stylet penetration difficulties; (4) $\mathrm{G}$ reflects active sap ingestion from xylem elements. Within the phloem phase, two waveforms occur; (5) E1 is the sieve element salivation; (6) E2 is the phloem sap ingestion with concurrent salivation. When phloem sap ingestion E2 occurs, it is always preceded by phloem salivation E1, but E1 waveform may occur as single waveform, without a subsequent E2. Also, E1 events may occur intermittently alternating with E2 events. An event was considered as an uninterrupted period of a waveform. Fig. S1-Online Resource 1 [(in Electronic Supplementary Material (ESM)] shows an overview of the EPG monitoring and waveforms of $R$. padi feeding on $\mathrm{E}+$ and $\mathrm{E}-$ plants.

For the analysis, a total of 24 variables were calculated and characterized into four broad categories (Table 3): (1), mean number of times that an activity (or a particular waveform) occurred per insect (see Table 3, variables 1, 3, 5, $7,10,13,17$, and 20), (2) mean duration of an activity per insect (see Table 3, variables 2, 4, 6, 8, 11, 14, 16, 18, and 21), (3) mean time to the first occurrence per insect of an activity from the start of the experiment or the probe (see Table 3, variables 22 and 23), and (4) number or percentage of aphids that showed a particular activity per treatment (see Table 3, variables 9, 12, 15, 19, and 24) with special interest in the percentage of aphids performing sustained phloem ingestion (sE2: uninterrupted period of E2 longer than $10 \mathrm{~min}$ ).

\section{Endophyte effect on aphid standard metabolic rate (SMR)}

SMR was used as an integrative measurement of the energetic expenditure (Nespolo et al. 2008). SMR was measured as the production of $\mathrm{CO}_{2}\left(\mathrm{VCO}_{2}\right)$ of each aphid group (see below) within an open-flow respirometry system (LI6400; Li-Cor, Lincoln, USA). Five individuals of adult and no-winged $R$. padi were transferred to $10 \mathrm{E}+$ and 10 E- plants of L. multiflorum. Plants were 16 weeks old (tillering-reproductive stage) and were grown as set up in experiment 1 . Immediately, each plant was covered with a plastic ceiling, and plants were carried to experimental chamber $\left[21^{\circ} \mathrm{C}( \pm 1)\right.$, photoperiod $\mathrm{L} 16$ :D8 $\mathrm{h}$, and radiation $150 \mu \mathrm{mol} \mathrm{m}^{-2} \mathrm{~s}^{-1}$ ] for 15 days. At day 15, 30-40 adult aphids of similar body size (no-winged) were carefully removed from each plant with a manual vacuum and placed in Eppendorf tubes. We considered each group of aphids (from one individual plant) as a replicate. Each replicate was weighted in an analytical balance $( \pm 0.0001 \mathrm{~g}$ Mettler Toledo $)$ and kept without food for $1 \mathrm{~h}$ before the metabolic measurements (to avoid measuring energy consumption related to digestion). Each aphid group was placed in metabolic chambers 
$(10 \mathrm{~mL})$ for $10 \mathrm{~min}$ at $25^{\circ} \mathrm{C}( \pm 0.5)$. Metabolic chambers received $\mathrm{CO}_{2}$-scrubbed air (with a Drierite column) with a mass flow controller (Sierra Instruments, Monterey, CA, USA) at a rate of $70 \mathrm{~mL} \mathrm{~min}{ }^{-1}$, which ensured adequate air mixing. This system measured the instantaneous $\mathrm{VCO}_{2}$ every second. SMR was estimated as the continuous range of the most stable 2-min samples recorded, and this value was divided by the number of aphids in the tube giving $\mu \mathrm{L}$ of $\mathrm{VCO}_{2}$ produced per individual per hour. Aphids were discarded after the SMR measurements.

\section{Statistical analyses}

Endophyte effect on aphid population dynamics and structure The aphid population size was measured as the number of aphids per individual plant. As was above-mentioned, counting of aphids was done each 3 days until day 25 . We analyzed the population size of aphids (number of aphids $\times$ plant $^{-1}$ ) during the counting times using generalized linear mixed effects models with the package lme4 in R software, assuming Poisson distribution of the response variable. The fixed part of the model included the symbiotic status (E+, E- plants) as categorical factor and the experimental time, and the random part the timelpot factor. Data overdispersion was not detected. The structure of the aphid population was measured as the number of nymphs and adults (apterous + winged). We reduced the structure to two aphid categories (number of nymphs and adult) lumping apterous and winged aphids. The structure of aphid populations was analyzed with generalized linear model using binomial distribution (nymph and adults aphid categories) and logit link function with the stats package in R software (Crawley 2007; Zuur et al. 2009). The model included the symbiotic status (E+, E- plants) as categorical/fixed factor.

Endophyte effect on individual aphid performance and development In this section, we characterized the morphology and development of aphids during two stages of their lifetime, nymph, and adult. On each stage, the aphid morphology was described with the variables length and weight, and the aphid development was with the variables life span, fecundity, and birth rate (as nymphs are not reproductive, fecundity and birth rate were not recorded). All these variables were analyzed separately with linear mixed effects models using the package nlme in $\mathrm{R}$ software and normal distribution (Pinheiro et al. 2009). The fixed part of the models of each response variable included the symbiotic status (E+ and $\mathrm{E}-$ plants) as categorical factor, and the random part the clip cagelpot factor. The number of models were 8 ( 3 for nymphs +5 for adult aphids). Only in the case of nymph's length and weight variables, the model included additionally the covariates' length and weight of mother aphids, respectively. Problems of variance hetero- geneity were detected on the endophyte factor, which were ameliorated using varIdent variance structure (Pinheiro et al. 2009). After that, ANOVA assumptions were met. The results were analyzed with ANOVA.

Endophyte effect on aphid feeding behavior A total of 24 variables were obtained and individually analyzed (Table 3 ). From these, 19 were calculated for insects on each plant treatment using the BAZ Excel workbook for calculation of aphid EPG variables (Edgar Schliephake, http://www. epgsystems.eu/downloads.php), and the other 5 variables were calculated manually (Table 3 ; variables 9, 12, 15, 19, and 24). Out of the 96 variables that the workbook calculates, we selected those usually listed as the most descriptive for aphid probing and feeding behavior in plant-aphids interactions evaluated with EPG (Chen et al. 1997; Klingler et al. 1998; Sarria et al. 2009; Cui et al. 2012; Alvarez et al. 2013; Machado-Assefh et al. 2015). The most part of the EPG variables were not strongly correlated $(r<0.65)$ [see Table S1-Online Resource 2 in Electronic Supplementary Material (ESM)]. The Mann-Whitney U rank sum tests were used to test for differences between aphids feeding on E- and E+ plants, because EPG variables did not follow a normal distribution (Table 3, variables 1-8, 10-11, 13-22). The Fisher's exact test was used to evaluate the difference in proportions of individuals performing a certain type of activity on $\mathrm{E}-$ and $\mathrm{E}+$ plants (Table 3, variables 9, 12, 15, 23 , and 24).

The levels of significance were adjusted for multiple testing using the false discovery rate (FDR) correction method at $\alpha=0.05$ (Benjamini and Hochberg 1995). A complete description of the FDR procedure is shown in (Benjamini et al. 2001). All statistical analyses for this experiment were performed using InfoStat Professional v2011p software (Di Rienzo et al. 2011).

Endophyte effect on aphid standard metabolic rate (SMR) The energetic expenditure of aphids feeding on endophytic plants was measured as the SMR by means of the aphids' production of $\mathrm{CO}_{2}\left(\mathrm{VCO}_{2}\right)$ (Nespolo et al. 2008). The relationship between SMR and endophyte status (as categorical factor, E+ and E-) was examined using ANCOVA, including the weight (body mass) of aphids as continuous covariate. Model was run using the function gls (from package nmle), assuming a normal distribution (Pinheiro et al. 2009). To linearize the relationship between aphid SMR and body mass, data were rescaled to $\eta \mathrm{LCO}_{2} \mathrm{~h}^{-1}$ and $\mu \mathrm{g}$, respectively, and then $\log 10$-transformed (to avoid negative values). Problems with normality were detected, which were fixed using VarPower variance structure on the covariate weight of aphids. After that, all the ANCOVA assumptions were achieved. Lineal regressions parameters 
were expressed in Log10-scale. Data were back-transformed to build the respective figure.

\section{Results}

\section{Endophyte effect on aphid population dynamics and structure}

The endophyte effect on the dynamics of aphid population size depended on the interaction with experimental time (Endophyte $\times$ Time: $F_{1,170}=8.90, P=0.002$; Endophyte: $F_{1,170}=8.95, P=0.002$; Time: $F_{1,170}=1424.37, P<0.001$ ). Starting with 10 aphids per plant, the population of aphids grew more rapidly and reached the population peak earlier on E- plants than on endophyte E+ plants (Fig. 1, left). When populations reached the highest population size $(\mathrm{d}$ 21 ), the average population of aphids on E+ plants was $64 \%$ smaller than the populations of aphids on E- plants.

The proportion of nymphs over the total population (nymphs + apterous and winged adults) was significantly affected on $\mathrm{E}+$ plants $\left(F_{1,30}=1.30, P=0.020\right)$. The nymph instar represented $81 \%$ of the aphid population feeding on E- plants, while only $14 \%$ of the population on E+ plants (Fig. 1, right). On the contrary, winged adults represented only $8 \%$ of the aphid population feeding on E- plants, while the $39 \%$ of the population on $\mathrm{E}+$ plants $\left(F_{1,14}=312.94\right.$, $P<0.001$ ) (Fig. 1, right).

\section{Endophyte effect on aphid individual performance and development}

Instar nymphs and adults were smaller (11 and 20\% lower, respectively) when fed on E+ plants than on E- plants (Table 2). The same pattern was observed on body mass (14 and 25\% lower for nymph and adult, respectively) (Table 2). While nymph length was not correlated with adult length, nymph weight was correlated with adult weight (Table 2). Endophyte affected the life span of only the adult aphids, which was shortened by 7 days (Table 2). During the whole period, the fecundity (total number of nymphs produced by an adult) was reduced by $50 \%$ in aphids feeding on E+ plants, while the daily fecundity (birth rate) was only reduced a $26 \%$ (Table 2 ).

\section{Endophyte effect on aphid feeding behavior (EPG)}

During the first $8 \mathrm{~h}$ of feeding, endophyte did not affect the aphids' probing, pathway, cell puncture, phloem ingestion, and xylem ingestion (Table 3). Aphids feeding on E+ plants showed less penetration difficulties activities than aphids feeding on E- plants, and the percentage of aphids that had penetration difficulties was lower on $\mathrm{E}+$ than on $\mathrm{E}$ - plants;
Table 2 Response variables length, weight, life span, fecundity, and birth rate of each instar (nymph and apterous adult) of the aphid Rhopalosiphum padi feeding on symbiotic $(25 \mathrm{E}+)$ and non-symbiotic (25 E-) Lolium multiflorum plants with the fungus Epichloë occultans

\begin{tabular}{|c|c|c|c|c|c|}
\hline Variables & E- & $\mathrm{E}+$ & $d f$ & $F$ & $P$ value \\
\hline \multicolumn{6}{|c|}{ Morphological } \\
\hline \multicolumn{6}{|c|}{ Length (mm) } \\
\hline Nymph & $0.89(0.01)$ & $0.79(0.01)$ & 1.48 & 163.99 & $<0.001$ \\
\hline Adult & $2.38(0.01)$ & $1.91(0.01)$ & 1.49 & 786.45 & $<0.001$ \\
\hline \multicolumn{6}{|c|}{ Weight (mg) } \\
\hline Nymph & $1.28(0.00)$ & $1.09(0.01)$ & 1.48 & 242.41 & $<0.001$ \\
\hline Adult & $0.32(0.00)$ & $0.24(0.01)$ & 1.49 & 146.00 & $<0.001$ \\
\hline \multicolumn{6}{|c|}{ Developmental } \\
\hline \multicolumn{6}{|c|}{ Life span (d) } \\
\hline Nymph & $7.18(0.01)$ & $7.19(0.01)$ & 1.48 & 0.80 & 0.380 \\
\hline Adult & $22.99(0.06)$ & $15.54(0.25)$ & 1.48 & 832.58 & $<0.001$ \\
\hline \multicolumn{6}{|c|}{ Fecundity (\#) } \\
\hline Nymph & - & - & & & \\
\hline Adult & $50.96(0.54)$ & $25.17(0.66)$ & 1.48 & 829.87 & $<\mathbf{0 . 0 0 1}$ \\
\hline \multicolumn{6}{|c|}{$\begin{array}{c}\text { Birth rate (\#. } \\
\left.\text { day }^{-1}\right)\end{array}$} \\
\hline Nymph & - & - & & & \\
\hline Adult & $2.22(0.02)$ & $1.64(0.05)$ & 1.48 & 92.84 & $<\mathbf{0 . 0 0 1}$ \\
\hline
\end{tabular}

Statistically significant comparisons (E+ vs. E-) are highlighted in bold. For the analysis of length and weight of nymph, the variables' length $\left(F_{1,48}=1.15, P=0.29\right)$ and weight $\left(F_{1,48}=5.26, P=0.03\right)$ of the mothers were used as covariate $(\mathrm{CoV})$, respectively. Values are mean $\pm \mathrm{SE}$

however, these differences were not significant after that FDR correction was applied (Table 3, variables 8 and 9).

\section{Endophyte effect on the metabolic rate of aphids}

There was a positive relationship between SMR and the body mass of aphids $\left(F_{1,16}=30.66, P<0.001\right)$ depending on whether they were feeding on $\mathrm{E}+$ and on $\mathrm{E}-$ plants (Fig. 2). Regression lines for $\mathrm{E}+$ and $\mathrm{E}-$ differed at the intercepts (intercepts, $\mathrm{E}+=0.69 \pm 0.46, \mathrm{E}-=0.77 \pm 0.03$, $F_{1,16}=30.17, P<0.001$ ) but not with the slopes (mean slope $=0.82 \pm 0.17, F_{1,16}=0.35, P=0.560$ ). In general, aphids feeding on $\mathrm{E}+$ plants presented $11 \%$ lower SMR than aphids feeding on E- plants (Fig. 2).

\section{Discussion}

Our results suggest that endophytes have a profound impact on physiology of aphids which scales up from the individual to population levels. We observed that aphids growing on E+ plants had lower SMR and body size, which correlated with lower vital rates and population growth. Consequently, 
Table 3 Feeding behavior of 8-h EPG monitoring of the aphid Rhopalosiphum padi on symbiotic (E+) $(n=22)$ and non-symbiotic (E-) ( $n=18$ ) Lolium multiflorum plants with the fungal endophyte Epichloë occultans

\begin{tabular}{|c|c|c|c|c|c|c|}
\hline Activity related (waveform) & EPG variable & Unit & E- & $\mathrm{E}+$ & $\mathrm{U}_{(1)}$ & $P$ \\
\hline \multirow[t]{2}{*}{ Probing (all waveforms) } & 1. Number of probing events & $\mathrm{N}$ & $5.61(1.18)$ & $5.18(1.47)$ & 391.50 & 0.536 \\
\hline & 2. Total time on probing & Min & $450.80(5.89)$ & $456.86(4.57)$ & 341.50 & 0.455 \\
\hline \multirow[t]{2}{*}{ Pathway (C) } & 3. Number of pathway events & $\mathrm{N}$ & $8.89(1.61)$ & $8.50(2.27)$ & 412.50 & 0.236 \\
\hline & 4. Total time on pathway & Min & $78.29(12.77)$ & $61.25(10.39)$ & 411.50 & 0.248 \\
\hline \multirow[t]{2}{*}{ Cell puncture (pd) } & 5. Number of pd events & $\mathrm{N}$ & $47.67(8.52)$ & $41.50(9.12)$ & 404.50 & 0.334 \\
\hline & 6. Total time on pd & Min & $3.34(0.57)$ & $2.66(0.46)$ & 406.50 & 0.308 \\
\hline \multirow[t]{3}{*}{ Derailed stylet mechanics $(\mathrm{F})$} & 7. Number of derailed stylet mechanics events & $\mathrm{N}$ & $0.83(0.23)$ & $0.45(0.25)$ & 427.00 & 0.057 \\
\hline & 8. Total time on derailed stylet mechanics & Min & $20.21(6.87)$ & $5.49(3.22)$ & 436.00 & $0.029 *$ \\
\hline & 9. Aphids showing derailed stylet mechanics & $\#(\%)$ & $9(50)$ & $4(18)$ & - & $0.046^{\mathrm{a} *}$ \\
\hline \multirow[t]{3}{*}{ Xylem phase (G) } & 10. Number of xylem phase events & $\mathrm{N}$ & $0.11(0.08)$ & $0.18(0.08)$ & 355.00 & 0.538 \\
\hline & 11. Total time on xylem phase & Min & $3.13(2.20)$ & $4.97(3.22)$ & 355.00 & 0.540 \\
\hline & 12. Aphids showing xylem phase & $\#(\%)$ & $2(11)$ & $4(18)$ & - & $0.673^{\mathrm{a}}$ \\
\hline \multirow[t]{12}{*}{ Phloem phase (E1 and E2) } & 13. Number of phloem salivation events (E1) & $\mathrm{N}$ & $3.39(0.69)$ & $3.82(0.79)$ & 373.50 & 0.899 \\
\hline & 14. Total time on salivation (E1) & Min & $4.08(2.26)$ & $3.94(1.88)$ & 365.50 & 0.924 \\
\hline & 15. Aphids showing phloem salivation (E1) & $\#(\%)$ & $18(100)$ & $22(100)$ & - & $1.000^{\mathrm{a}}$ \\
\hline & 16. Total time on phloem phase $(\mathrm{E} 1+\mathrm{E} 2)$ & Min & $346.56(18.73)$ & $383.20(14.52)$ & 316.50 & 0.153 \\
\hline & 17. Number of phloem ingestion events (E2) & $\mathrm{N}$ & $2.94(0.56)$ & $3.32(0.68)$ & 371.00 & 0.955 \\
\hline & 18. Total time on phloem ingestion (E2) & Min & $345.09(18.75)$ & $381.21(14.66)$ & 308.50 & 0.100 \\
\hline & 19. Aphids showing phloem ingestion & $\#(\%)$ & $18(100)$ & $22(100)$ & - & $1.000^{\mathrm{a}}$ \\
\hline & $\begin{array}{l}\text { 20. Number of sustained phloem ingestion events } \\
\text { (sE2, E2 event }>10 \text { min) }\end{array}$ & $\mathrm{N}$ & $1.94(0.26)$ & $2.14(0.30)$ & 359.50 & 0.783 \\
\hline & 21. Total time of sustained phloem ingestion (sE2) & $\min$ & $341.30(19.26)$ & $378.21(15.37)$ & 305.50 & 0.084 \\
\hline & 22. Time to 1 st phloem salivation (E1) & $\min$ & $71.28(15.62)$ & $45.84(6.99)$ & 397.50 & 0.438 \\
\hline & 23. Time to 1st sustained phloem ingestion (sE2) & $\min$ & $80.58(17.54)$ & $46.37(7.02)$ & 402.50 & 0.362 \\
\hline & 24. Aphids showing sustained phloem ingestion & $\#(\%)$ & $18(100)$ & $22(100)$ & - & $1.000^{\mathrm{a}}$ \\
\hline
\end{tabular}

EPG waveforms; C, stylet penetration pathway movements; pd, potential drops due to brief intracellular stylet punctures; F, stylet penetration difficulties; G, active sap ingestion from xylem elements; E1, sieve element salivation; E2, phloem sap ingestion with concurrent salivation. " $U$ " column indicates the Mann-Whitney $\mathrm{U}$ values (with $d f=1$ )

${ }^{a}$ Variables analyzed with Fisher's exact test (with $d f=1$ ). ${ }^{*} P$ values $\leq 0.050$ that are not significant after controlling for multiple testing (FDR, see text for details). Values are mean \pm SE. $N$, and Min indicates number and minutes, respectively

aphids had a dramatic change in the population structure; population of aphids on E+ plants had a lower proportion of nymphs and a higher number of winged adults. When considering variables related with aphid feeding behavior, none of them resulted affected by the presence of fungal endophytes.

Based on the metabolic load hypothesis, insects feeding on plants with toxic secondary compounds would have an extra-cost of energy spent in detoxification, which would ultimately reduce the energy allocated to growth and reproduction (Cody 1966; Cresswell et al. 1992; Karban and Agrawal 2002; Castañeda et al. 2009). We expected that aphids growing on E+ plants would incur high energetic costs associated to the detoxification of fungal alkaloids, and as a result, they would show impaired growth and reproduction. Indeed, we found that aphids feeding on E+ plants had severely affected morphometric (lower length and weight) and functional (shorter adult life span and lower fecundity) variables of individual performance. In addition, the poor individual performance had consequences at the population level, which was appreciated on the birth rate (lower on E+ plants), on population structure (fewer nymphs and many winged adults), and on population size (smaller populations). Our results are in line with previous studies using the same grass-endophyte-herbivore combination (see Omacini et al. 2001; Miranda et al. 2011; Gundel et al. 2012; Ueno et al. 2015). However, the metabolic measurements were in the opposite direction to our expectations. Aphids showed lower values of SMR on E+ than on E- plants suggesting no additional energetic costs for alkaloid detoxification. Similar contradictory results have been found in other grass-herbivore systems (Neal 1987; Appel and Martin 1992; van Loon 1993). These studies suggest that lower metabolic rates could be explained by changes in feeding behavior (e.g., decreasing food intake) and/or changes in feeding efficiency (e.g., decreasing assimilation efficiency). 


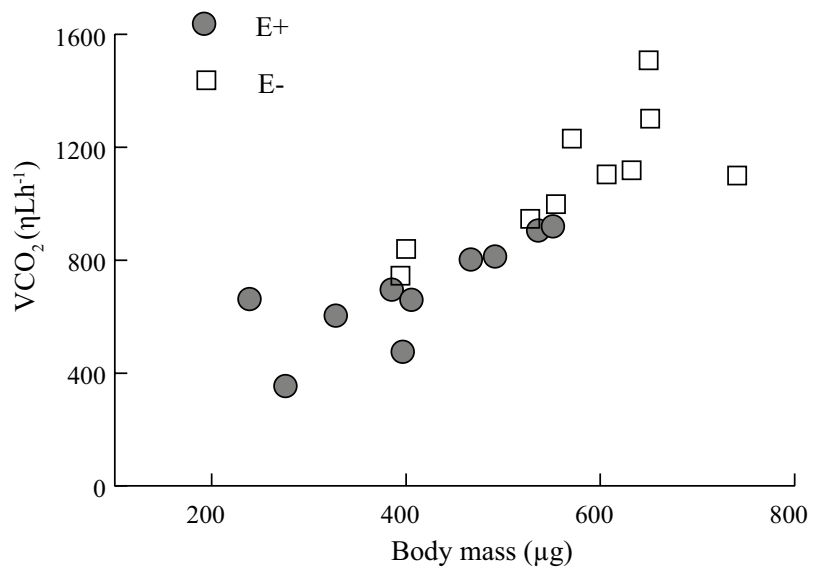

Fig. 2 Relationship between SMR $\left(\mathrm{VCO}_{2}\right)$ and body mass of individual aphids (Rhopalosiphum padi) feeding on symbiotic $(\mathrm{E}+; n=10)$ and non-symbiotic (E-; $n=10)$ Lolium multiflorum plants with the fungus Epichloë occultans. Data were back-transformed to build the figure (see "Materials and methods" section). Regression lines from transformed data were E+: $\log _{10} \operatorname{VCO}_{2}\left(\eta \mathrm{L} \mathrm{h}^{-1}\right)=0.69+0.82 \times \log _{10}$ body mass $(\mu \mathrm{g})$; and $\mathrm{E}-$ : $\log _{10} \mathrm{VCO}_{2}\left(\eta \mathrm{L} \mathrm{h}^{-1}\right)=0.77+0.82 \times \log _{10}$ body mass $(\mu \mathrm{g})$

We evaluated the aphids feeding behavior during the first $8 \mathrm{~h}$ of contact with $\mathrm{E}+$ or E- plants. Given that time of food transit through the digestive system of aphids is around of $1 \mathrm{~h}$ (Schoonhoven et al. 2005), aphids would have had enough time to show changes in feeding behavior due to the presence of alkaloids in E+ plants. Based on the observed values of SMR, we expected that aphids feeding on E+ plants had a reduced level of phloem ingestion. However, aphids did not show any change in the ingestion of phloem on $\mathrm{E}+$ and $\mathrm{E}-$ plants. We hypothesize that the reduction of phloem ingestion occurs only when the amount of ingested alkaloids overcome the aphid tolerance threshold. Thus, it is likely that during the first hours of contact with E+ plants, the level of ingested alkaloids has been within the aphid's tolerance limits. However, a longer period of time feeding on E+ plants would have overcome the alkaloid tolerance threshold decreasing the ingestion of phloem. In fact, changes in food intake have been observed within a few hours of exposing insects to endophytic alkaloids. For instance, larvae of the Japanese beetle Popilia japonica growing for $24 \mathrm{~h}$ on diets containing endophytic ergotamine decreased the ingestion of food (Grewal et al. 1995). Moreover, changes in the aphid food ingestion would be expected considering that $R$. padi aphids always tend to prefer $\mathrm{E}-$ plants in choice experiments (where insects are allowed to choose between E+ and E- plants) (Johnson et al. 1985; Eichenseer et al. 1991; Eichenseer and Dahlman 1992; Davidson and Potter 1995; Bultman et al. 2006). Whether this hypothesis is correct or not requires further studies.

This work contributes to our understanding of how a loline-producing fungal endophyte may influence the aphid population dynamics studying the insect behavioral and physiological responses and also highlights interesting questions necessary to appreciate the complete trophic interaction between endophyte, host, and herbivore. Although our study could not find a direct causal relation between the physiological and behavioral responses with the individual performance and the population processes of aphids, the changes observed in the insect's physiological status (SMR) and in the population growth dynamic could be explained by the differential phloem ingestion on $\mathrm{E}+$ and $\mathrm{E}-$ plants. Therefore, future studies would be required to monitor how the individual feeding behavior is directly related to population growth dynamics. Thus, the feeding behavior could be an aspect key to understand the changes at individual and population levels observed in aphids. Another interesting aspect to explore is the biochemical detoxification response of aphids to toxic fungal alkaloids. The endophyte $E$. occultans is known to produce lolines (Sugawara et al. 2006; Moore et al. 2015) whose chemical natures are lipophilic (Petroski et al. 1989). To cope with lipophilic toxins, there are a group of conserved enzymes required for detoxification such as the superfamilies of cytochrome P450 monooxygenases, the glutathione S-transferases, and the esterases (Després et al. 2007; Castañeda et al. 2010). It would be particularly important to evaluate whether aphids express or upregulate these enzymes in response to feeding on E+ plants. Our results of SMR and individual performance suggest that the aphid's biochemical detoxification capacity had been overcome at the later stages of the population growth.

Acknowledgements The manuscript was significantly improved by the constructive work made by two anonymous reviewers. We gratefully acknowledge Dr. Edmundo L. Ploschuk (Universidad de Buenos Aires) for assistance with the metabolic measurements. This work was funded by the Agencia Nacional de Promoción Científica FONCYT (PICT-2355) and the Universidad de Buenos Aires UBA (UBACYT 2014-30BA).

Author contribution statement DAB, PEG originally formulated the idea; DAB, ACU, CRMA, AEA developed methodology and performed statistical analyses; CAY performed molecular analyses; DAB wrote the manuscript.

\section{Compliance with ethical standards}

Conflict of interest The authors declare that they have no conflict of interest.

\section{References}

Alvarez AE, Broglia VG, Alberti D’Amato AM et al (2013) Comparative analysis of Solanum stoloniferum responses to probing by the green peach aphid Myzus persicae and the potato aphid Macrosiphum euphorbiae. Insect Sci 20:207-227. doi:10.1111/j.1744-7917.2012.01505.x 
Appel HM, Martin MM (1992) Significance of metabolic load in the evolution of host specificity of Manduca sexta. Ecology 73:216228. doi:10.2307/1938733

Bacon CW, White JF Jr (1994) Stains, media, and procedures for analyzing endophytes. In: Bacon CW, White JF Jr (eds) Biotechnology of endophytic fungi of grasses. CRC Press, Boca Raton, pp 47-56

Behmer ST, Elias DO, Bernays EA (1999) Post-ingestive feedbacks and associative learning regulate the intake of unsuitable sterols in a generalist grasshopper. J Exp Biol 202:739-748

Benjamini Y, Hochberg Y (1995) Controlling the false discovery rate: a practical and powerful approach to multiple testing. J R Stat Soc Ser B Methodol 57:289-300

Benjamini Y, Drai D, Elmer G et al (2001) Controlling the false discovery rate in behavior genetics research. Behav Brain Res 125:279284. doi:10.1016/S0166-4328(01)00297-2

Bennett AE, Alers-Garcia J, Bever JD (2006) Three-way interactions among mutualistic mycorrhizal fungi, plants, and plant enemies: hypotheses and synthesis. Am Nat 167:141-152. doi:10.1086/499379

Berry D, Takach JE, Schardl CL et al (2015) Disparate independent genetic events disrupt the secondary metabolism gene perA in certain symbiotic Epichlö̈ species. Appl Environ Microbiol 81:2797-2807. doi:10.1128/aem.03721-14

Bultman TL, Bell G, Martin WD (2004) A fungal endophyte mediates reversal of wound-induced resistance and constrains tolerance in a grass. Ecology 85:679-685. doi:10.1890/03-0073

Bultman TL, Pulas C, Grant L et al (2006) Effects of fungal endophyte isolate on performance and preference of bird cherry-oat aphid. Environ Entomol 35:1690-1695. doi:10.1093/ee/35.6.1690

Castañeda LE, Figueroa CC, Fuentes-Contreras E et al (2009) Energetic costs of detoxification systems in herbivores feeding on chemically defended host plants: a correlational study in the grain aphid, Sitobion avenae. J Exp Biol 212:1185-1190. doi:10.1242/ jeb.020990

Castañeda LE, Figueroa CC, Fuentes-Contreras E et al (2010) Physiological approach to explain the ecological success of "superclones" in aphids: interplay between detoxification enzymes, metabolism and fitness. J Insect Physiol 56:1058-1064. doi:10.1016/j.jinsphys.2010.02.019

Charlton ND, Craven KD, Afkhami ME et al (2014) Interspecific hybridization and bioactive alkaloid variation increases diversity in endophytic Epichloë species of Bromus laevipes. FEMS Microbiol Ecol 90:276-289. doi:10.1111/1574-6941.12393

Chen JQ, Rahbé Y, Delobel B et al (1997) Melon resistance to the aphid Aphis gossypii: behavioural analysis and chemical correlations with nitrogenous compounds. Entomol Exp Appl 85:33-44. doi:10.1046/j.1570-7458.1997.00232.x

Clay K (1988) Fungal endophytes of grasses: a defensive mutualism between plants and fungi. Ecology 69:10-16. doi: $10.2307 / 1943155$

Cody ML (1966) A general theory of clutch size. Evolution 20:174184. doi: $10.2307 / 2406571$

Crawley MJ (2007) The R book. Wiley, Oxford

Cresswell J, Merritt S, Martin M (1992) The effect of dietary nicotine on the allocation of assimilated food to energy metabolism and growth in fourth-instar larvae of the southern armyworm, Spodoptera eridania (Lepidoptera: Noctuidae). Oecologia 89:449-453. doi:10.1007/BF00317425

Cui L, Sun L, Yang D et al (2012) Effects of cycloxaprid, a novel cis-nitromethylene neonicotinoid insecticide, on the feeding behaviour of Sitobion avenae. Pest Manag Sci 68:1484-1491. doi:10.1002/ps.3333

Davidson AW, Potter DA (1995) Response of plant-feeding, predatory, and soil-inhabiting invertebrates to Acremonium endophyte and nitrogen fertilization in tall fescue turf. J Econ Entomol 88:367379. doi:10.1093/jee/88.2.367

Després L, David J-P, Gallet C (2007) The evolutionary ecology of insect resistance to plant chemicals. Trends Ecol Evol 22:298 307. doi:10.1016/j.tree.2007.02.010

Di Rienzo JA, Casanoves F, Balzarin MG et al (2011) InfoStat versión 2011. Grupo InfoStat, FCA, Universidad Nacional de Córdoba, Buenos Aires

Eichenseer H, Dahlman DL (1992) Antibiotic and deterrent qualities of endophyte-infected tall fescue to two aphid species (Homoptera: Aphididae). Environ Entomol 21:1046-1051. doi:10.1093/ ee/21.5.1046

Eichenseer H, Dahlman DL, Bush LP (1991) Influence of endophyte infection, plant age and harvest interval on Rhopalosiphum padi survival and its relation to quantity of $N$-formyl and $\mathrm{N}$-acetyl loline in tall fescue. Entomol Exp Appl 60:29-38. doi:10.1111/j.1570-7458.1991.tb01519.x

Fuchs B, Krischke M, Mueller M, Krauss J (2013) Peramine and lolitrem B from endophyte-grass associations cascade up the food chain. J Chem Ecol 39:1385-1389. doi:10.1007/ s10886-013-0364-2

Grewal SK, Grewal PS, Gaugler R (1995) Endophytes of fescue grasses enhance susceptibility of Popillia japonica larvae to an entomopathogenic nematode. Entomol Exp Appl 74:219-224. doi:10.1111/j.1570-7458.1995.tb01894.x

Gundel PE, Martínez-Ghersa MA, Omacini M et al (2012) Mutualism effectiveness and vertical transmission of symbiotic fungal endophytes in response to host genetic background. Evol Appl 5:838-849. doi:10.1111/j.1752-4571.2012.00261.x

Gundel PE, Pérez LI, Helander M, Saikkonen K (2013) Symbiotically modified organisms: nontoxic fungal endophytes in grasses. Trends Plant Sci 18:420-427. doi:10.1016/j.tplants.2013.03.003

Herrera CM, Pellmyr O (2002) Plant animal interactions: an evolutionary approach. Blackwell Sciences Ltd, Oxford

Ibanez S, Gallet C, Després L (2012) Plant insecticidal toxins in ecological networks. Toxins 4:228-243. doi:10.3390/toxins 4040228

Johnson MC, Dahlman DL, Siegel MR et al (1985) Insect feeding deterrents in endophyte-infected tall fescue. Appl Environ Microbiol 49:568-571

Johnson L, de Bonth AM, Briggs L et al (2013) The exploitation of epichloae endophytes for agricultural benefit. Fungal Divers 60:171-188. doi:10.1007/s13225-013-0239-4

Karban R, Agrawal AA (2002) Herbivore offense. Annu Rev Ecol Syst 33:641-664. doi:10.2307/3069275

Karban R, Baldwin I (1997) Induced responses to herbivory. The University of Chicago Press, Chicago

Kimmins FM, Tjallingii WF (1985) Ultrastructure of sieve element penetration by aphid stylets during electrical recording. Entomol Exp Appl 39:135-141. doi:10.1111/j.1570-7458.1985.tb03554.x

Klingler J, Powell G, Thompson GA, Isaacs R (1998) Phloem specific aphid resistance in Cucumis melo line AR 5: effects on feeding behaviour and performance of Aphis gossypii. Entomol Exp Appl 86:79-88. doi:10.1046/j.1570-7458.1998.00267.x

Koricheva J, Gange AC, Jones T (2009) Effects of mycorrhizal fungi on insect herbivores: a meta-analysis. Ecology 90:2088-2097. doi:10.1890/08-1555.1

Machado-Assefh CR, Lopez-Isasmendi G, Tjallingii WF et al (2015) Disrupting Buchnera aphidicola, the endosymbiotic bacteria of Myzus persicae, delays host plant acceptance. Arthropod Plant Interact 9:529-541. doi:10.1007/s11829-015-9394-8

McLean DL, Kinsey MG (1964) A Technique for electronically recording aphid feeding and salivation. Nature 202:1358-1359. doi: $10.1038 / 2021358 \mathrm{a} 0$

Meister B, Krauss J, Härri SA et al (2006) Fungal endosymbionts affect aphid population size by reduction of adult life span and fecundity. Basic Appl Ecol 7:244-252. doi:10.1016/j.baae.2005.06.002 
Miranda MI, Marina O, Chaneton EJ (2011) Environmental context of endophyte symbioses: interacting effects of water stress and insect herbivory. Int J Plant Sci 172:499-508. doi:10.1086/658921

Moon CD, Scott B, Schardl CL, Christensen MJ (2000) The evolutionary origins of Epichloë endophytes from annual ryegrasses. Mycologia 92:1103-1118. doi:10.2307/3761478

Moore JR, Pratley JE, Mace WJ, Weston LA (2015) Variation in alkaloid production from genetically diverse Lolium accessions infected with Epichloë species. J Agric Food Chem 63:1035510365. doi:10.1021/acs.jafc.5b03089

Müller CB, Williams IS, Hardie J (2001) The role of nutrition, crowding and interspecific interactions in the development of winged aphids. Ecol Entomol 26:330-340. doi:10.1046/j.1365-2311.2001.00321.x

Neal JJ (1987) Metabolic costs of mixed-function oxidase induction in Heliothis zea. Entomol Exp Appl 43:175-179. doi:10.1111/j.1570-7458.1987.tb03602.x

Nespolo RF, Roff DA, Fairbairn DJ (2008) Energetic tradeoff between maintenance costs and flight capacity in the sand cricket (Gryllus firmus). Funct Ecol 22:624-631. doi:10.1111/j.1365-2435.2008.01394.x

Oliver TH, Mashanova A, Leather SR et al (2007) Ant semiochemicals limit apterous aphid dispersal. Proc R Soc B Biol Sci 274:3127. doi:10.1098/rspb.2007.1251

Omacini M, Chaneton EJ, Ghersa CM, Muller CB (2001) Symbiotic fungal endophytes control insect host-parasite interaction webs. Nature 409:78-81. doi:10.1038/35051070

Omacini M, Chaneton EJ, Bush L, Ghersa CM (2009) A fungal endosymbiont affects host plant recruitment through seedand litter-mediated mechanisms. Funct Ecol 23:1148-1156. doi:10.1111/j.1365-2435.2009.01582.x

Panaccione DG, Beaulieu WT, Cook D (2014) Bioactive alkaloids in vertically transmitted fungal endophytes. Funct Ecol 28:299314. doi:10.1111/1365-2435.12076

Patch EM (1917) Eastern aphids, new or little known, part I. J Econ Entomol 10:416-420. doi:10.1093/jee/10.4.416

Petroski RJ, Yates SG, Weisleder D, Powell RG (1989) Isolation, semi-synthesis, and nmr spectral studies of loline alkaloids. J Nat Prod 52:810-817. doi:10.1021/np50064a023

Phillips NW (1984) Compensatory intake can be consistent with an optimal foraging model. Am Nat 123:867-872. doi: $10.1086 / 284246$

Pieterse CMJ, Zamioudis C, Berendsen RL et al (2014) Induced systemic resistance by beneficial microbes. Annu Rev Phytopathol 52:347-375. doi:10.1146/annurev-phyto-082712-102340

Pineda A, Zheng S-J, van Loon JJA et al (2010) Helping plants to deal with insects: the role of beneficial soil-borne microbes. Trends Plant Sci 15:507-514. doi:10.1016/j.tplants.2010.05.007

Pinheiro J, Bates D, DebRoy S et al (2009) nlme: linear and nonlinear mixed effects models. R Package. R Foundation for Statistical Computing, Vienna

Popay AJ, Bonos SA (2005) Biotic responses in endophytic grasses. In: Roberts CA, West CP, West DES (eds) Neotyphodium in cool-season grasses. Blackwell Publishing, New Jersey, pp $163-185$

Pozo MJ, Azcón-Aguilar C (2007) Unraveling mycorrhiza-induced resistance. Curr Opin Plant Biol 10:393-398. doi:10.1016/j. pbi.2007.05.004

Rollo CD, Hawryluk MD (1988) Compensatory scope and resource allocation in two species of aquatic snails. Ecology 69:146-156. doi: $10.2307 / 1943169$

Rueda A, Slansky F Jr, Wheeler G (1991) Compensatory feeding response of the slug Sarasinula plebeia to dietary dilution. Oecologia 88:181-188. doi:10.1007/BF00320809
Saikkonen K, Gundel P, Helander M (2013) Chemical ecology mediated by fungal endophytes in grasses. J Chem Ecol 39:962-968. doi:10.1007/s10886-013-0310-3

Sarria E, Cid M, Garzo E, Fereres A (2009) Excel workbook for automatic parameter calculation of EPG data. Comput Electron Agric 67:35-42. doi:10.1016/j.compag.2009.02.006

Schardl CL, Young CA, Faulkner JR et al (2012) Chemotypic diversity of Epichloae, fungal symbionts of grasses. Fungal Ecol 5:331-344. doi:10.1016/j.funeco.2011.04.005

Schardl CL, Young C, Pan J et al (2013a) Currencies of mutualisms: sources of alkaloid genes in vertically transmitted Epichloae. Toxins 5:1064-1088. doi:10.3390/toxins5061064

Schardl CL, Florea S, Pan J et al (2013b) The Epichloae: alkaloid diversity and roles in symbiosis with grasses. Curr Opin Plant Biol 16:480-488. doi:10.1016/j.pbi.2013.06.012

Schardl CL, Young CA, Hesse U et al (2013c) Plant-symbiotic fungi as chemical engineers: multi-genome analysis of the clavicipitaceae reveals dynamics of alkaloid loci. PLoS Genet 9:e1003323. doi:10.1371/journal.pgen.1003323

Schoonhoven LM, van Loon JJA, Dicke M (2005) Insect-plant biology. Oxford University Press Inc., New York

Simons L, Bultman T, Sullivan TJ (2008) Effects of methyl jasmonate and an endophytic fungus on plant resistance to insect herbivores. J Chem Ecol 34:1511-1517. doi:10.1007/ s10886-008-9551-y

Simpson SJ, Abisgold JD (1985) Compensation by locusts for changes in dietary nutrients: behavioural mechanisms. Physiol Entomol 10:443-452. doi:10.1111/j.1365-3032.1985.tb00066.x

Speed MP, Fenton A, Jones MG et al (2015) Coevolution can explain defensive secondary metabolite diversity in plants. New Phytol 208:1251-1263. doi:10.1111/nph.13560

Su J, Zhu S, Zhang Z, Ge F (2006) Effect of synthetic aphid alarm pheromone (E)- $\beta$-farnesene on development and reproduction of Aphis gossypii (Homoptera: Aphididae). J Econ Entomol 99:1636-1640. doi:10.1093/jee/99.5.1636

Sugawara K, Inoue T, Yamashita M, Ohkubo H (2006) Distribution of the endophytic fungus, Neotyphodium occultans in naturalized Italian ryegrass in western Japan and its production of bioactive alkaloids known to repel insect pests. Grassl Sci 52:147-154. doi:10.1111/j.1744-697X.2006.00060.x

Takach JE, Young CA (2014) Alkaloid genotype diversity of tall fescue endophytes. Crop Sci. doi:10.2135/cropsci2013.06.0423

Tjallingii WF (1978) Electronic recording of penetration behaviour by aphids. Entomol Exp Appl 24:721-730. doi:10.1111/j.1570-7458.1978.tb02836.x

Tjallingii WF (1985) Electrical nature of recorded signals during stylet penetration by aphids. Entomol Exp Appl 38:177-186. doi:10.1111/j.1570-7458.1985.tb03516.x

Tjallingii WF (1988) Electrical recording of stylet penetration activities. In: Minks AK, Harrewijn P (eds) Aphids, their biology, natural enemies and control. Elsevier, Amsterdam, pp 95-108

Tjallingii WF, Esch TH (1993) Fine structure of aphid stylet routes in plant tissues in correlation with EPG signals. Physiol Entomol 18:317-328. doi:10.1111/j.1365-3032.1993.tb00604.x

Traicevski V, Ward SA (1994) Birth weight and the rate of increase in the cowpea aphid Aphis craccivora (Homoptera: Aphididae). Eur J Entomol 91:37-46

Ueno AC, Gundel PE, Omacini M et al (2015) Mutualism effectiveness of a fungal endophyte in an annual grass is impaired by ozone. Funct Ecol 30:226-232. doi:10.1111/1365-2435.12519

van Loon JJA (1993) Gravimetric vs. respirometric determination of metabolic efficiency in caterpillars of Pieris brassicae. Entomol Exp Appl 67:135-142. doi:10.1111/j.1570-7458.1993. tb01661.x 
Walters DR (2011) Plant defense: warding off attack by pathogens, herbivores, and parasitic plants, 1st edn. Blackwell Publishing Ltd., Oxford

White JF, Torres MS (2009) Defensive mutualism in microbial symbiosis. CRC Press, Boca Raton

Wilkinson HH, Siegel MR, Blankenship JD et al (2000) Contribution of fungal loline alkaloids to protection from aphids in a grassendophyte mutualism. Mol Plant Microbe Interact 13:10271033. doi:10.1094/MPMI.2000.13.10.1027
Young CA, Schardl CL, Panaccione DG et al (2015) Genetics, genomics and evolution of ergot alkaloid diversity. Toxins 7:1273-1302. doi:10.3390/toxins 7041273

Zuur AF, Ieno EN, Walker NJ et al (2009) Mixed effects models and extensions in ecology with R, 1st edn. Springer, New York 